\title{
Subject-object subextraction asymmetry in Russian
}

\author{
Daria Belova \\ Department of Theoretical and Applied Linguistics, Lomonosov Moscow State \\ University, Russia \\ https://doi.org/10.36505/ExLing-2020/11/0012/000427
}

\begin{abstract}
Subject-object asymmetry in wh-subextraction is relevant in many languages, but the degree of subject opacity is not crosslinguistically uniform and can differ within one language. In (Polinsky et al. 2013) two factors are found statistically significant in Russian dependent clauses: the type of verbal structure (unaccusative / unergative / transitive verb) and the position of a subject relatively to a verb (preverbal / postverbal). In this paper we investigate whether the effect of these variables is preserved in Russian monopredicative independent clauses. Using experimental data, we show that different types of subjects do differ in their island properties, however, contra (Polinsky et al. 2013), in the preverbal position they are significantly more transparent to subextraction.
\end{abstract}

Keywords: subject-object asymmetry, wh-movement, word order, argument structure, topicality

\section{Subject-object subextraction asymmetry}

The opacity to subextraction of subject NPs relatively to object NPs was first captured by Ross (1967) and formulated as Sentential Subject Island Constraint (SSIC). Later this constraint was extended by Chomsky (1973) as Subject Condition and by Huang (1982) as Condition on Extraction Domain (CED): only complement position is transparent to subextraction.

However, the properties of subject islands are found not to be crosslinguistically uniform (see e.g. (Stepanov 2007). Subject NPs show different levels of opacity not only in different languages, but also within one language. These facts led to several theories explaining subject island constraints. Wexler and Culicover (1981) explain the asymmetry with the socalled freezing effect: a constituent becomes opaque after it has been moved out of its deriving position. Another approach is based on discourse-related topic opacity: only foci can undergo subextraction (see (Goldberg 2006)).

In this paper we explore two factors that are known to affect the subject NPs' opacity: verbal argument structure and word order. Subjects of different types of verbal structure are modelled as having different deriving position: a subject of unaccusative verbs is derived in a VP complement just like an object of a transitive verb, and subjects of transitive and unergative verbs are derived

ExLing 2020: Proceedings of $11^{\text {th }}$ International Conference of Experimental Linguistics, 12-14 October 2020, Athens, Greece 
in spec,vP. According to CED an unaccusative subject would be more transparent to subextraction than an unergative and a transitive subjects, but the mentioned approaches don't make such predictions. Change in word order is relevant because (i) non-basic word orders, if they are possible, demand movement from in situ position, what helps testing the freezing approach; (ii) the leftmost position is related to focus position, therefore, can provide evidence for the topic opacity approach.

\section{Subject-object asymmetry in Russian Previous research}

Polinsky et al. (2013) were first to experimentally test the two factors mentioned above on Russian material. The authors investigated four types of NPs (subjects of unaccusative, unergative and transitive verbs and an object of a transitive verb) and two positions of NP relatively to a verb in Russian and found that (i) unaccusative subjects are indeed more transparent than subjects of the two other types, transitive subjects are the most opaque ones; (ii) objects in a preverbal position are opaque to subextraction. It is important to say that the researchers investigated only arguments within a dependent clause. However, Kush (2018) shows that the distance of movement is also relevant to island properties. For this reason, we have conducted our experimental investigation addressing the following research question: How the acceptability of subextraction from structurally different subjects and an object depends on the position of the subextraction site with respect to the verb in a monopredicative clause?

\section{Current study}

The experimental design included two independent variables: NP type (unaccusative, unergative, transitive subjects and a transitive object) and NP position (XV, VX where V stands for a verb and X stands for an NP). Half of the intransitive stimuli had a postverbal adjunct and half of the transitive stimuli had animate object. All the sentences began with wh-particle $\check{c} \ddot{i}$ "whose", which was separated from a verb and its arguments by a time adverbial to make subextraction more obvious and avoid potential misinterpretations. One experimental block contained eight conditions. Three lexicalizations were made for each experimental condition, so there were 24 test stimuli in each experimental list and eight lists in total. Experimental lists also contained 24 fillers of two types: grammatical and ungrammatical. The ungrammatical ones included a filled gap in the place of wh-extraction. Respondents were asked to rate stimuli out of context on a Likert scale from 1 ("very bad sentence") to 7 ("very good sentence").

To check if non-basic word orders (VS for intransitive verbs, OSV/VOS/VSO for transitive verbs) could worsen the rating of the stimuli we have conducted 
a pilot experiment. It had the same structure as the main experiment and shared the same lexicalizations but contained sentences without whextraction. The ungrammatical fillers contained mistakes in subject-verb agreement markers or incoherence between a time adjunct and verbal aspect. 103 Russian native speakers completed the pilot experiment (53 females), ranging from age 13 to 67 (mean $=33) .171$ respondents participated in the main experiment (86 females), ranging from age 16 to 64 (mean $=34)$. The ratings of each respondent in both experiments were normalized to minimize personal tendencies in using the scale.

The results of the pilot experiment have shown that non-basic word orders do worsen ratings, so it provides us a baseline to estimate the role of these factors un the main experiment.

Finally, the main experiment showed the following results. According to ANOVA both NP type and NP position have significant effect on ratings. Besides, (i) the preverbal position is significantly less opaque to subextraction than the postverbal position for each type of NP, including the object; (ii) in the preverbal position all subjects are rated the same and the object is rated lower; (iii) in the postverbal position unaccusative subject is the most(?) transparent, unergative subject is rated lower and both arguments of transitive verb are rated almost equally as the less transparent (the statistical difference between them is marginal):

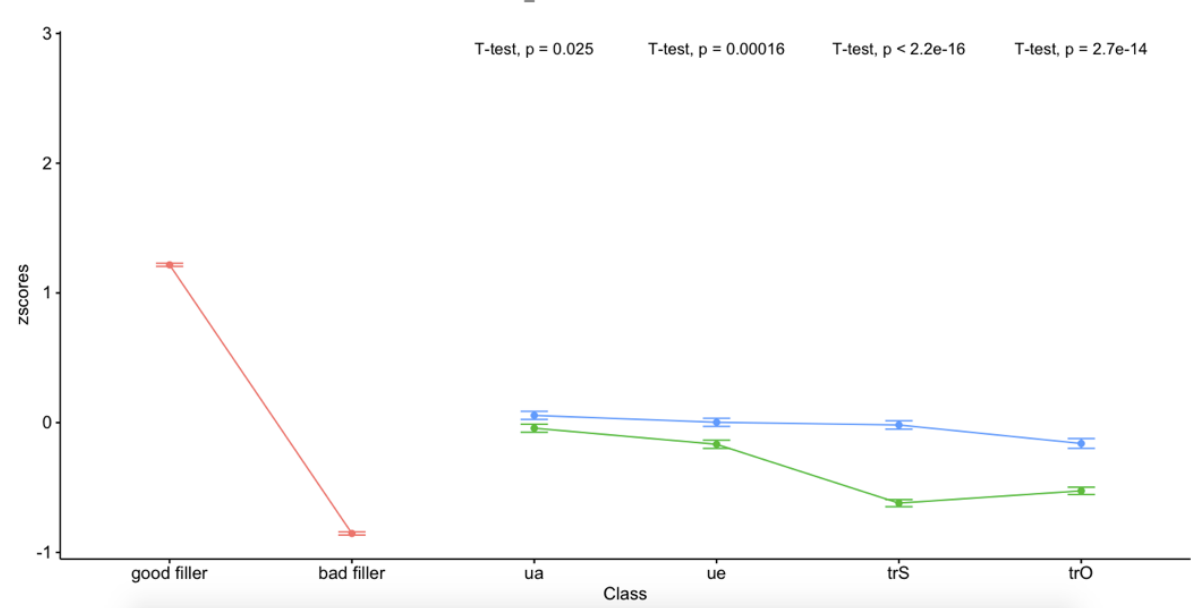

Figure 1. The interaction plot with the factors NP type and NP position and the ratings of the two types of fillers. On the top of the plot the results of the Student's t-test application to pairwise comparisons of two positions for each verb type are presented. $U a, u e, t r S$, trO stand for unaccusative, unergative and transitive subjects and object.

These results are remarkable from two points of view. Firstly, our findings contrast with the results of (Polinsky et al. 2013): in our experiment the object 
NP is far less opaque and the position of NP has much stronger effect on the ratings of subextraction from every type of subject. Secondly, the obtained results are not consistent with predictions of the three presented approaches. Nevertheless, our results support the hierarchy found in (Polinsky et al. 2013): the unaccusative subextraction gets the highest ratings and subextraction from the transitive subjects gets the lowest ones. Thus, our results suggest that the distance of movement is a relevant factor for Russian subject island properties.

\section{References}

Chomsky, N. 1973. Conditions on transformations. In Anderson, S., Kiparsky, P. (eds). 1973. A festschrift for Morris Halle, 232-286. New York: Holt: Rinehart \& Winston.

Goldberg, A. 2006. Constructions at Work: The nature of generalization in language. Oxford: Oxford University Press.

Huang, C.-T.J. 1982. Logical relations in Chinese and the theory of grammar. Ph.D. dis. Massachusetts University of Technology.

Kush, D., Lohndal, T., Sprouse, J. 2018. Investigating variation in island effects. A case study of Norwegian wh-extraction. Natural language and linguistic theory 36. 743 779 .

Polinsky, M. et al. Subject islands are different. In Sprouse, J., Hornstein, N. (eds). 2013. Experimental syntax and island effects, 286-309. Cambridge: Cambridge University Press.

Ross, J.R. 1967. Constraints on variables in syntax. Ph.D. dis. Massachusetts Institute of Technology.

Stepanov, A. 2007. The end of CED? Minimalism and extraction domain. Syntax 10(1), 80-126.

Wexler, K., Culicover, P. 1981. Formal principles of language acquisition. Cambridge, Mass.: MIT Press. 